\title{
Loan guarantee portfolios and joint loan guarantees with stochastic interest rates
}

\author{
Chuang-Chang Chang ${ }^{\mathrm{a}, *}$, San-Lin Chung ${ }^{\mathrm{b}}$, Min-Teh $\mathrm{Yu}^{\mathrm{c}}$ \\ a Department of Finance, National Central University, Jung-Li 32001, Taiwan \\ ${ }^{\mathrm{b}}$ Department of Finance, National Taiwan and National Central Universities, Taipei, Taiwan \\ c Department of Finance, Providence University, Taichung 43301, Taiwan
}

Received 16 January 2003; accepted 28 July 2003

\begin{abstract}
Most papers studying loan guarantee are under a one-borrower and one-guarantor framework. This study uses the option approach to construct models in which loan guarantees are analyzed under a multiple-borrower and one-guarantor framework and under a one-borrower and multiple-guarantor structure with stochastic interest rates. We carry out simulations to investigate how the important parameters of borrowers and guarantors affect the values and default probability of loan guarantees. Our results show that the correlation parameters play a critical role in determining the premiums of loan guarantee portfolios and joint loan guarantees.
\end{abstract}

(C) 2003 Board of Trustees of the University of Illinois. All rights reserved.

JEL classification: G13

Keywords: Default probability; Loan guarantee portfolios; Joint loan guarantees

\section{Introduction}

Financial guarantee insurance is a commitment by a third party to make payment in the event of default on a financial contract. Usually, a bank, an insurance company, and/or different levels of government stand as third party. Financial guarantee insurance as such

\footnotetext{
* Corresponding author. Tel.: +8863 426 2308; fax: +88634252961.

E-mail address: ccchang@cc.ncu.edu.tw (C.-C. Chang).
} 
has become increasingly widespread with the development of securitization of various types of loans and the growth of off-balance-sheet guarantees by commercial banks, insurance companies and government agencies. Since financial guarantees are popular in the world, it has become an important issue that researchers develop models to estimate the fair values of guarantee contracts.

Merton (1977) first illustrates that a loan guarantee is analogous to that of a put option and derives a closed-form solution to estimate the values of deposit insurance guarantees. Jones and Mason (1980) construct valuation models of loan guarantees with a riskless guarantor. Their simulation results show that the value of a loan guarantee rises, as the risk represented by the variance of return on the borrowing firm's assets increases.

Chen, Chen, and Sears (1986) develop a model to examine the effects of loan guarantees on the outstanding debts of Chrysler. Johnson and Stulz (1987) derive a formula for calculating the value of an insured, risky discount bond with default risk. Selby, Franks, and Karki (1988) use the Geske (1979) compound option approach to value the loan guarantee provided by the British government to International Computer Limited and compare the size and direction of the consequent wealth transfer to and from bondholders. Merton and Bodie (1992) show the purchase of any loan, whether or not the guarantees are explicit, is equivalent to purchasing a pure default-free loan and the simultaneous issue of a guarantee on that loan.

Lai (1992) constructs a discrete-time model to analyze vulnerable loan guarantees under different conditions of debt subordination. Lai and Gendron (1994) extend to value private financial guarantees under stochastic interest rates. Lai and Yu (1999) compute the values of the guaranteed and unguaranteed subordinated loan and compare the accurate results obtained by numerical integration techniques with those approximated from the closedform formula. More recently, Dermine and Lajeri (2001) introduce lending risk explicitly in the literature on market-based estimation of deposit insurance premium.

All of the above-mentioned literature constructs models that value loan guarantee contracts under a one-borrower and one-guarantor framework. However, many real world cases for loan guarantees are one-borrower and multiple-guarantor, or multiple-borrower and oneguarantor. For example, one financial institution acts as the guarantor for several loans of different firms at the same time, or a large firm with a huge amount of loans seeks several banks or insurance companies as its guarantor at the same time. For these cases, the models existing in the literature cannot directly be used to estimate the loan guarantee values.

The contributions of this paper are twofold. First, we construct a model in which a loan guarantee is analyzed under a one-borrower and multiple-guarantor framework with stochastic interest rates. Second, we analyze a loan guarantee under a multiple-borrower and one-guarantor structure with stochastic interest rates. We carry out simulations to investigate how the important parameters of borrowers and guarantors affect the values and default probability of guarantee contracts in both cases. Hence, our paper fills in the existing gap in the literature and provides solutions for valuing the loan guarantee for a general framework.

The article continues with Section 2 constructing a model, which estimates the value of loan guarantees for the case of multiple-guarantees and one-guarantor with stochastic interest rates. Section 3 follows the analysis of Section 2 to develop a model for estimating the value of loan guarantees for the case of one-guarantee and multiple-guarantor. Section 4 carries out simulations to investigate how the important parameters of guarantees and 
guarantor affect the values and default probability of guarantee contracts in both cases. Section 5 draws forth conclusions.

\section{The model for loan guarantee portfolio}

In this section, we construct a model to estimate the values of loan guarantees for the case of multiple-borrower and one-guarantor with stochastic interest rates. In the subsequent context, we adopt the following assumptions:

- The capital market is perfectly competitive with no transaction costs, no taxes, and equal access to information for all investors with symmetric information.

- No dividend and coupon payments. There are no payouts from either the firms of borrowers or their guarantor to shareholders and bondholder before the maturity date of the discount bond.

- The borrowers' asset values and the guarantor's asset value are multivariate lognormally distributed.

- We ignore all potential agency problems inherent to financial contracting.

- No-arbitrage opportunity exists. All securities with identical payoffs sell at the same price.

Let $W(T)$ and $H$ denote the end-of-period asset value and the senior debt value of the guarantor firm, respectively. Assume that there are $n$ borrowing firms (guarantees). Let $V_{i}(T)$, $D_{i}(T), E_{V_{i}}(T)$, and $F_{i}(i=1,2, \ldots, n)$ represent the end-of-period asset value, the senior debt value, the equity value, and the junior guaranteed debt face value of the borrowing firm $i$, respectively. We can use a simple $T$ account to present the capital structure of the $i$ borrowing firm and the guarantor as follows:

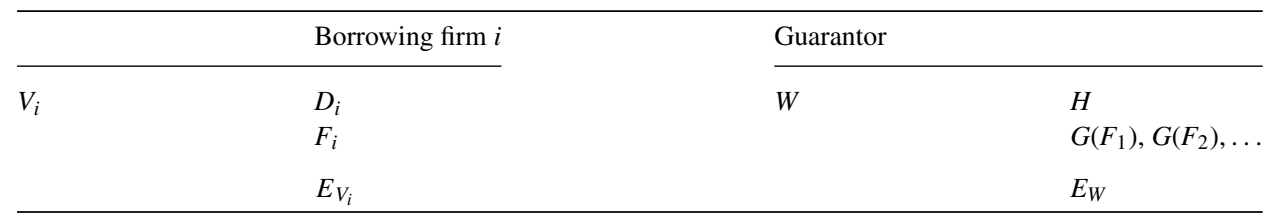

At maturity date, $T$, if the residual value of the end-of-period asset after payments of senior debt is less than the face value of its corresponding junior guaranteed debt, then the borrowing firm is bankrupt. The shortage for paying the guaranteed debt face value is compensated by the guarantor in the amount of the guarantor's asset value minus its senior debt value. Hence, to own the junior guaranteed debt of borrowing firms is similar to holding the subordinated debt of the guarantor.

Assume that the owners of the borrowing firm $i(i=1,2, \ldots, n)$ have equal protection from the guarantor. When the guarantor's end-of-period asset value after payment of senior debt is less than the shortage between the residual value of the borrowing firms' asset values after paying their senior debts and their debt face value, the guarantor is bankrupt. In such a case, the guarantor can only proportionally compensate the holders of junior guaranteed bonds of the borrowing firms. 
Based on the above setting, the total shortage between the residual value of all borrowing firms' asset values after paying their senior debts and their junior guaranteed debt face values is

$$
X(T)=\sum_{j=1}^{n} \min \left\{\alpha_{j} F_{j}, \max \left[F_{j}-\max \left[V_{j}(T)-D_{j}(T), 0\right], 0\right]\right\},
$$

where $\alpha_{j}$ is the protected proportion of the insured bonds of borrowing firm $j$. It is straightforward to show that the proportionally compensated value from the guarantor for the holders of junior guaranteed bond of borrowing firm $i$

$$
R_{i}(T)=\frac{\min \left\{\alpha_{i} F_{i}, \max \left[F_{i}-\max \left[V_{i}(T)-D_{i}(T), 0\right], 0\right]\right\} \max [W(T)-H, 0]}{X(T)} .
$$

Therefore, the payoffs $B_{\mathrm{g} i}$ for the owners of junior guaranteed debt of borrowing firm $i$, at time $T$, can be expressed as follows:

$$
B_{\mathrm{g} i}(T)=\min \left\{\max \left[V_{i}(T)-D_{i}(T), 0\right]+R_{i}(T), F_{i}\right\} .
$$

It should be noted that if the borrowing firm $i$ is not bankrupt, the compensated value $R_{i}(T)$ is zero.

We construct an artificial asset, $Q_{i}$, with the value as follows:

$$
Q_{i}=\max \left[V_{i}(T)-D_{i}(T), 0\right]+R_{i}(T) .
$$

We then have

$$
\begin{aligned}
B_{\mathrm{g} i}(T) & =\min \left[Q_{i}(T), F_{i}\right]=F_{i}+\min \left[Q_{i}(T)-F_{i}, 0\right]=F_{i}-\max \left[F_{i}-Q_{i}(T), 0\right] \\
& =F_{i}-\operatorname{Put}\left(Q_{i}(T), F_{i}, T\right),
\end{aligned}
$$

where $\operatorname{Put}\left(Q_{i}(T), F_{i}, T\right)$ is the time $T$ value of the European put option with strike price $F_{i}$ and underlying asset price $Q_{i}(T)$.

The holders of the debts without guarantee of borrowing firm $i$ at maturity date $T$ have the payoffs, $B_{i}(T)$, with the value as follows:

$$
B_{i}(T)=\min \left\{\max \left[V_{i}(T)-D_{i}(T), 0\right], F_{i}\right\} .
$$

Since the guaranteed value of a loan with a risky guarantor equals the value of loan without guarantee minus the value of a loan with guarantee, the value of guarantee $G_{i}$ at time $T$ for borrowing firm $i$ can be simply expressed as follows:

$$
\begin{aligned}
G_{i}(T) & =B_{\mathrm{g} i}(T)-B_{i}(T)=\min \left[Q_{i}, F_{i}\right]-\min \left\{\max \left[V_{i}(T)-D_{i}(T), 0\right], F_{i}\right\} \\
& =\max \left\{F_{i}-\max \left[V_{i}(T)-D_{i}(T), 0\right], 0\right\}-\max \left[F_{i}-Q_{i}(T), 0\right] \\
& =\operatorname{Put}\left(\operatorname{Call}\left(V_{i}(T), D_{i}(T), T\right), F_{i}, T\right)-\operatorname{Put}\left(Q_{i}(T), F_{i}, T\right) .
\end{aligned}
$$

The third equality in the above equation comes from the fact that $\min (a, b)=b-\max (a-b$, 0 ). Discounting and taking expectation of Eq. (5), we have the formula for calculating the 
value of loan guarantee for borrowing firm $i$, that is

$$
G_{i}(0)=E\left[\mathrm{e}^{-\int_{0}^{T} r(\tau) \mathrm{d} \tau} G_{i}(T)\right] .
$$

Apart from calculating the value of loan guarantee for borrowing firm $i$, we are also interested in how to compute the probability of default for the risky guarantor. The economic condition for the risky guarantor to default is when the guarantor's end-of-period asset value after payment of senior debt is less than the shortage between the residual value of the borrowing firms' asset values after payment of their senior debts and their junior guaranteed debt's face value. The condition of default for the risky guarantor can be defined as follows:

$$
W(T)-H<X(T) .
$$

Based on Eq. (7), one can calculate the probability of default for the risky guarantor by simulations. We will illustrate how to calculate this probability through the Monte-Carlo simulation in Section 4.

\section{The model for joint guarantees for loans}

In this section, we construct a model to estimate the values of loan guarantees for the case of one-borrower and multiple-guarantor with stochastic interest rates. The assumptions made in the previous section are still valid in the following context. Assume that there are $m$ guarantors for the loans of one borrowing firm. Let $W_{j}(T)(j=1,2, \ldots, m)$ and $H_{j}(T)(j=1,2, \ldots, m)$ denote the end-of-period asset value and the senior debt value of the $j$ guarantor, respectively. Since there is only one borrowing firm in this case, we let $V(T), D(T)$, and $F$ denote the end-of-period asset value, senior debt value, and insured junior debt face value of the borrowing firm, respectively. In the case of $V(T)-D(T)<F$, the borrowing firm is bankrupt and guarantors must share equally for the shortage value between $V-D$ and $F$. However, if some of the guarantors are also bankrupt at the same time, other guarantors have to share their losses.

Based on the above structure, we recognize that the end-of-period cost $\left(C_{j}(T)\right.$ ) (or the value of loan guarantee provided by guarantor $j$ ) for guarantor $j$ includes two parts. One is its own share of cost $\left(S_{j}(T)\right)$ for the loan guarantee of the borrowing firm. The other is the extra share of cost $\left(U_{j}(T)\right)$ belonging to the bankrupt guarantors. Its own share $\left(S_{j}(T)\right)$ of the $j$ guarantor for the loan guarantee can be expressed as follows:

$$
S_{j}(T)=\left\{\begin{array}{ll}
0, & \text { if } D(T)+F-V(T)<0, \text { else if } \\
\frac{1}{m} \min (D(T)+F-V(T), F), & W_{j}(T)-H_{j}(T)>\frac{1}{m} \min (D(T)+F-V(T), F), \text { else if } \\
W_{j}(T)-H_{j}(T), & 0<W_{j}(T)-H_{j}(T)<\frac{1}{m} \min (D(T)+F-V(T), F), \text { else } \\
0, &
\end{array} .\right.
$$

Another expression for $S_{j}(T)$ is

$$
S_{j}(T)=\min \left\{\frac{1}{m} \min [\max (D(T)+F-V(T), 0), F], \max \left(0, W_{j}(T)-H_{j}(T)\right)\right\} .
$$


Let

$$
Y=\frac{1}{m} \min [\max (D(T)+F-V(T), 0, F)] .
$$

It follows that

$$
S_{j}(T)=\min \left[Y, \max \left(0, W_{j}(T)-H_{j}(T)\right)\right] .
$$

The extra share of cost $\left(U_{j}(T)\right)$ for guarantor $j$ is as following.

$$
\begin{aligned}
U_{j}(T)=\min \left\{\max \left[\max \left(W_{j}(T)-H_{j}(T), 0\right)-Y, 0\right],\right. & \\
& \left.\frac{1}{m-l} \sum_{i=1_{i \neq j}}^{m} \max \left[Y-\max \left(W_{i}(T)-H_{i}(T), 0\right), 0\right]\right\},
\end{aligned}
$$

where $l$ is the number of the bankrupt guarantor (not including guarantor $j$ ), that is

$$
l=\sum_{i=1_{i \neq j}}^{m} A_{i}, \quad A_{i}= \begin{cases}1, & \text { if } Y<\max \left(W_{i}(T)-H_{i}(T), 0\right) \\ 0, & \text { else }\end{cases}
$$

Hence, the end-of-period cost $\left(C_{j}(T)\right)$ for the $j$ guarantor can be obtained by following equation.

$$
C_{j}(T)=S_{j}(T)+U_{j}(T) .
$$

We are also interested in how to compute the default probability for the joint guarantee contract. The economic condition for the joint guarantee contract to default is when the guarantors' end-of-period asset values after payment of senior debts are less than the shortage between the residual value of the borrowing firm's asset value after payment of senior debt and its junior guaranteed debt face value. The condition of default for the joint guarantee contract can be defined as follows:

$$
\sum_{i=1}^{m} \max \left(W_{i}(T)-H_{i}(T), 0\right)<\min (F+D(T)-V(T), F) .
$$

Based on Eq. (12), we can directly calculate the default probability for the joint guarantee contract by simulations.

\section{Numerical methods}

Based on the model setting given in Sections 2 and 3, it is difficult, if not impossible, to obtain closed-form solutions for the values of loan guarantees. Hence, we employ Monte Carlo simulations to estimate the values of loan guarantees. The Monte Carlo simulation procedure for derivative pricing can be briefly described as follows: first, simulate sample paths for the underlying variables; second, compute its corresponding derivative payoff for 
each path; and finally, average the simulated payoffs and discount the average to yield the derivative price.

For the case of multiple-borrower and one-guarantor, we assume that the asset values of borrowing firms and the guarantor follow a geometric Brownian motion as given in Eq. (12).

$$
\begin{aligned}
& \frac{\mathrm{d} W}{W}=\mu_{W} \mathrm{~d} t+\sigma_{W} \varepsilon_{W} \sqrt{\mathrm{d} t}, \\
& \frac{\mathrm{d} V_{i}}{V_{i}}=\mu_{V_{i}} \mathrm{~d} t+\sigma_{V_{i}} \varepsilon_{V_{i}} \sqrt{\mathrm{d} t} \quad(i=1,2, \ldots, n),
\end{aligned}
$$

where $\mu_{W}\left(\mu_{V_{i}}\right)$ is the drift rate of the asset return of guarantor (borrower $i$ ), and $\sigma_{W}\left(\sigma_{V_{i}}\right)$ is the instantaneous volatility of the asset return of guarantor (borrower $i$ ), respectively. Additionally, $\varepsilon_{W}$ and $\varepsilon_{V_{i}}$ are standard normal random variables, and the correlation among them is $\rho_{V_{i}, W}$.

For the case of one-borrower and multiple-guarantor, we also similarly assume that the asset values of borrowing firms and the guarantor follow a geometric Brownian motion as given in Eq. (13).

$$
\begin{aligned}
& \frac{\mathrm{d} W_{j}}{W_{j}}=\mu_{W_{j}} \mathrm{~d} t+\sigma_{W_{j}} \varepsilon_{W_{j}} \sqrt{\mathrm{d} t} \quad(j=1,2, \ldots, m), \\
& \frac{\mathrm{d} V}{V}=\mu_{V} \mathrm{~d} t+\sigma_{V} \varepsilon_{V} \sqrt{\mathrm{d} t} .
\end{aligned}
$$

The notations in Eq. (13) are similar to those in Eq. (12).

Since we consider stochastic interest rate environments, we employ the Cox, Ingersoll, and Ross (1985) model to describe the dynamic process of interest rates. We express the interest rate process as follows:

$$
\mathrm{d} r=a(b-r) \mathrm{d} t+\sigma_{r} \sqrt{r} \varepsilon_{r} \sqrt{\mathrm{d} t},
$$

where $a$ and $b$ are the speed of mean reversion and the average long-term rate, respectively. This model incorporates mean reversion where the short rate is pulled to a level $b$ at a rate of $a$. Furthermore, let $\rho_{r, W}$ and $\rho_{r, V_{i}}$ denote the correlation coefficient between interest rate and the asset value of the guarantor, and the correlation coefficient between interest rate and the asset value of borrowing firm $i$.

We describe the process of generating random variables in Appendix A. The process presented in the appendix is general enough to pricing a derivative whose payoff depends on $n$ variables.

\section{Numerical results}

We conduct experiments to investigate how the important parameters of borrowers and guarantors affect the values and default probability of loan guarantees for both cases of loan guarantee portfolios and joint guarantees. Most of the parameter settings in this paper 
Table 1

Results of comparative static analysis for loan guarantee portfolio

$P=P\left(\sigma_{r}^{+}, \rho_{W, r}^{+}, \rho_{V_{2}, r}^{+}, H^{+}, d_{2}^{+}, f_{2}^{+}, \sigma_{W}^{+}, \sigma_{V_{2}}^{+}\right)$

$G_{1}=G_{1}\left(\sigma_{r}^{+}, \rho_{W, r}^{-}, \rho_{V_{2}, r}^{-}, H^{-}, d_{2}^{*}, f_{2}^{*}, \sigma_{W}^{-}, \sigma_{V_{2}}^{*}\right)$

$G_{2}=G_{2}\left(\sigma_{r}^{+}, \rho_{W, r}^{-}, \rho_{V_{2}, r}^{+}, H^{-}, d_{2}^{+}, f_{2}^{+}, \sigma_{W}^{-}, \sigma_{V_{2}}^{+}\right)$

are based on Lai and Gendron (1994). The initial guarantor firm value $(W(0))$ is chosen as 3.5 (million), the volatility of guarantor firm $\left(\sigma_{W}\right)$ value is $10 \%$, and the value of guarantor senior debt $(H)$ is 2 million. We set the initial firm value of borrower $i\left(V_{i}(0)\right)$ at 2.1 million, the volatility of the firm's value of borrower $i\left(\sigma_{V_{i}}\right)$ at $20 \%$, the value of borrower $i$ 's senior debt at 1 million, and the face value of insured debts of borrower $i\left(f_{i}\right)$ at 1 million. The coefficients of correlation between a risky guarantor's firm value and the borrower $(i)$ firm value are $\rho_{W, V_{i}}=0.3$ and $\rho_{V_{j}, V_{i}}=0.3$, respectively. Additionally, the coefficients of correlation between risky guarantor firm value, the value of borrowing firm $(i)$, and the interest rate are $\rho_{W, r}=0.3$ and $\rho_{V, r}=0.3$, respectively. ${ }^{1}$ We also set other interest rate parameters as follows: $\sigma_{r}=0.08544, a=4.2753$, and $b=0.08 .^{2}$ In the following analysis, we use 50,000 simulation runs $^{3}$ to calculate the values and default probability of loan guarantees.

\subsection{Results of loan guarantee portfolio}

For compactness, we report only those results for how changes in the covariance matrix, the values of guarantor and borrowers' senior debts, and the value of borrower's insured debt affect the value and default probability of loan guarantees under stochastic interest rates. ${ }^{4}$ Additionally, to simplify the analysis, we use the case of two borrowers and one guarantor $^{5}$ as an example to carry out simulations. From our numerical examples, we have the following signs for comparative static analysis.

In Table $1, P, G_{1}$, and $G_{2}$ stand for the default probability, the value of loan guarantee for borrowing firm one and the value of loan guarantee for borrowing firm two with stochastic interest rates, respectively. Like financial options, the loan guarantee values increase with the volatility of state variable. Additionally, the default probability also increases with the volatility of state variables, since increases in the volatility of the state variable will amplify the risks of the loan guarantee contracts.

We will first investigate the effects of changes in the correlation coefficient between the guarantor's firm value and the value of borrowing firm two $\left(\rho_{W, V_{2}}\right)$ on the loan guarantee value and default probability. From Fig. 1, we find that the higher $\rho_{W, V_{2}}$, the smaller is the

\footnotetext{
1 The correlation coefficients used here $(\rho=0.3)$ can guarantee that the correlation coefficient matrix is a positive definite matrix.

2 The settings of interest rate parameters in this paper are based on Chan, Karolyi, Longstaff, and Sanders (1992). We assume the market risk of interest rate $(\lambda)$ equal to zero since the estimated value for $\lambda$ is very small in Chan et al. (1992) paper.

3 The standard deviations of loan guarantee values are less $1 \%$ under 50,000 simulation runs.

${ }^{4}$ We perform the same simulation under constant interest rates. However, for conciseness, we did not report those results here.

${ }^{5}$ Our results remain valid for general cases.
} 


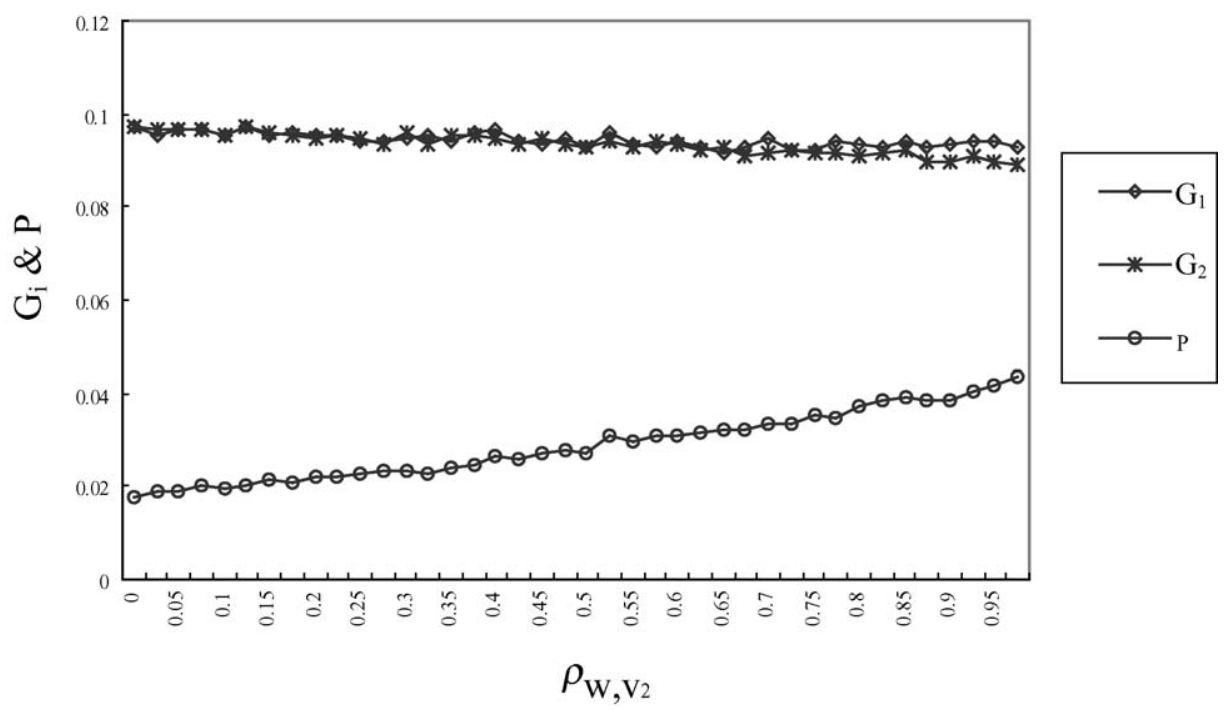

Fig. 1. The effects of a change in $\rho_{W, V_{2}}$ on the value of loan guarantee portfolio and default probability. $G_{1}$ represents the loan guarantee value (in terms of millions of dollars) for borrowing firm one, $G_{2}$ represents the loan guarantee value (in terms of millions of dollars) for borrowing firm two, and $P$ denotes the default probability of the loan guarantee contract, respectively.

loan guarantee value and the higher the default probability is. The reason for this result is that the higher $\rho_{W, V_{2}}$ is, the smaller is the risk diversification. Hence, when the correlation coefficient between the guarantor's firm value and the value of borrowing firm two increases, the loan guarantee values decrease and the default probability increases.

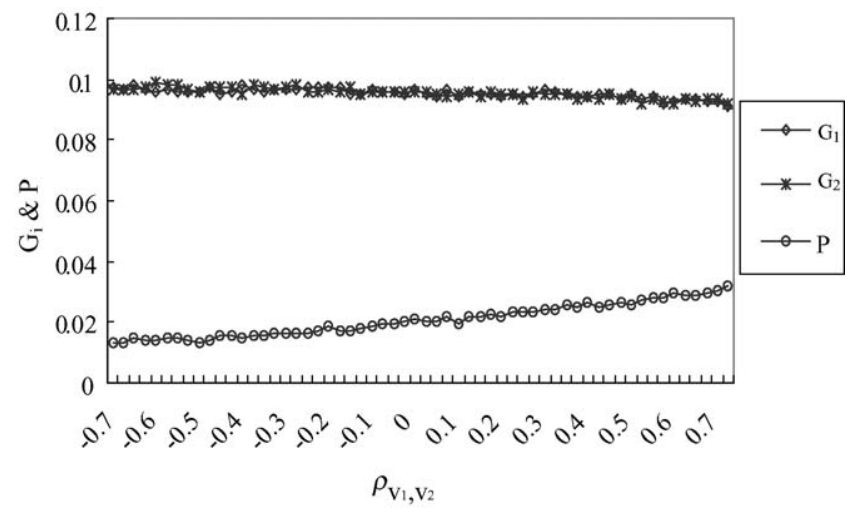

Fig. 2. The effects of a change in $\rho_{V_{1}, V_{2}}$ on the value of loan guarantee portfolio and default probability. $G_{1}$ represents the loan guarantee value (in terms of millions of dollars) for borrowing firm one, $G_{2}$ represents the loan guarantee value (in terms of millions of dollars) for borrowing firm two, and $P$ denotes the default probability of the loan guarantee contract, respectively. 


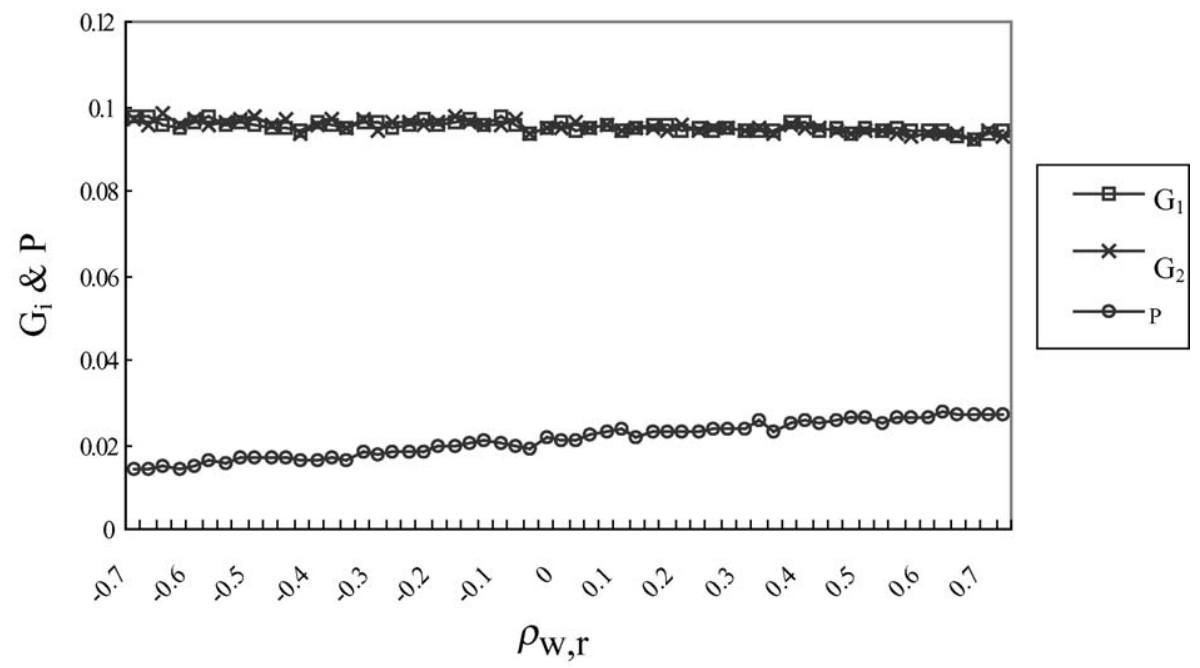

Fig. 3. The effects of a change in $\rho_{W, r}$ on the loan guarantee portfolio value and default probability. $G_{1}$ represents the loan guarantee value (in terms of millions of dollars) for borrowing firm one, $G_{2}$ represents the loan guarantee value (in terms of millions of dollars) for borrowing firm two, and $P$ denotes the default probability of loan guarantee contract, respectively.

Additionally, as reported in Fig. 2, the loan guarantee values decrease when the correlation coefficient between borrowing firm one's value and borrowing firms two's value increases. Furthermore, the default probability also increases when $\rho_{V_{1}, V_{2}}$ increases. The reason for the result is the same as that in Fig. 1.

Other important factors which could significantly affect the loan guarantee value are the correlation coefficient between the guarantor's firm value and the interest rate $\left(\rho_{W, r}\right)$, and the correlation coefficient between the borrowing firm value and interest rate $\left(\rho_{V_{i}, r}\right)$. As reported in Fig. 3, the higher the correlation coefficient is between the guarantor's firm value and the interest rate, the smaller is the loan guarantee value, and the higher is the default probability. The explanation for this result is that the growth rates of asset returns for a guarantor and borrowing firms are equal to the riskless interest rate in the risk-neutral world. Hence, the effect of an increase in the correlation coefficient between the guarantor's firm value and the interest rate is similar to the effect of an increase in the correlation coefficient between the guarantor's firm value and the borrowing firm's value.

We also find that the higher the correlation coefficient is between borrowing firm two's value and the interest rate, the smaller is the loan guarantee value for borrowing firm one, the higher is the loan guarantee value for borrowing firm two, and the higher is the default probability. The possible reason is that a higher $\rho_{V_{2}, r}$ means a larger amount of bankruptcy for borrowing firms. If the guarantor does not default, then the compensation for borrowing firm two will increase, and hence will increase the loan guarantee value for borrowing firm two. In contrast, the loan guarantee value for borrowing firm one will decrease due to the crowding out effect. 


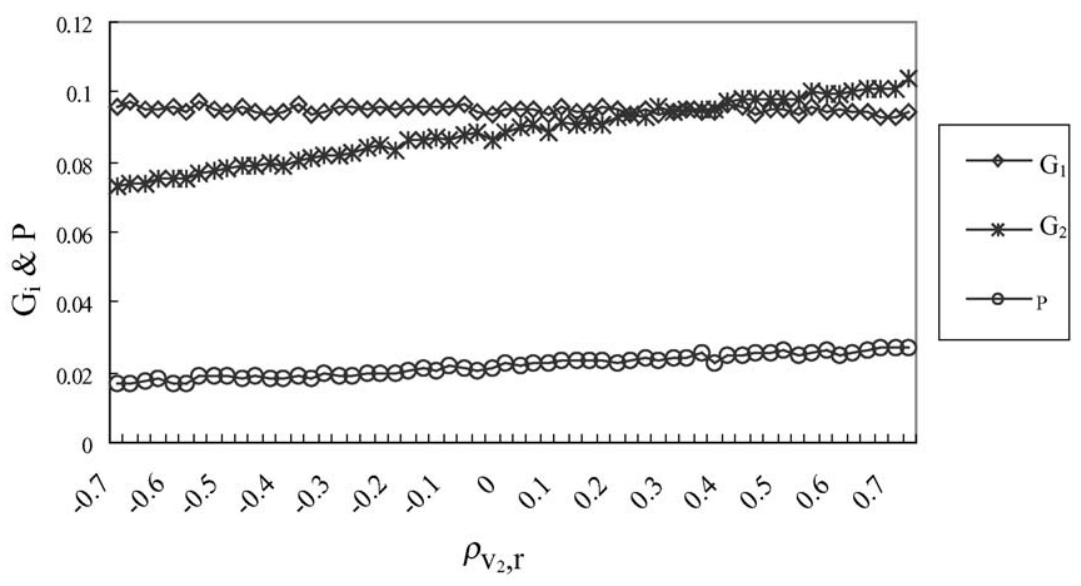

Fig. 4. The effects of a change in $\rho_{V_{2}, r}$ on the loan guarantee portfolio value and default probability. $G_{1}$ represents the loan guarantee value (in terms of millions of dollars) for borrowing firm one, $G_{2}$ represents the loan guarantee value (in terms of millions of dollars) for borrowing firm two, and $P$ denotes the default probability of loan guarantee contract, respectively.

The amount of the guarantor's senior debts is also an important factor, which affects the values of loan guarantee contracts. Figs. 4 and 5 illustrate that the larger the guarantor's senior debts are, the smaller is the loan guarantee value and the higher is the default probability. We know that the compensation amount for the guarantees is equal to the difference

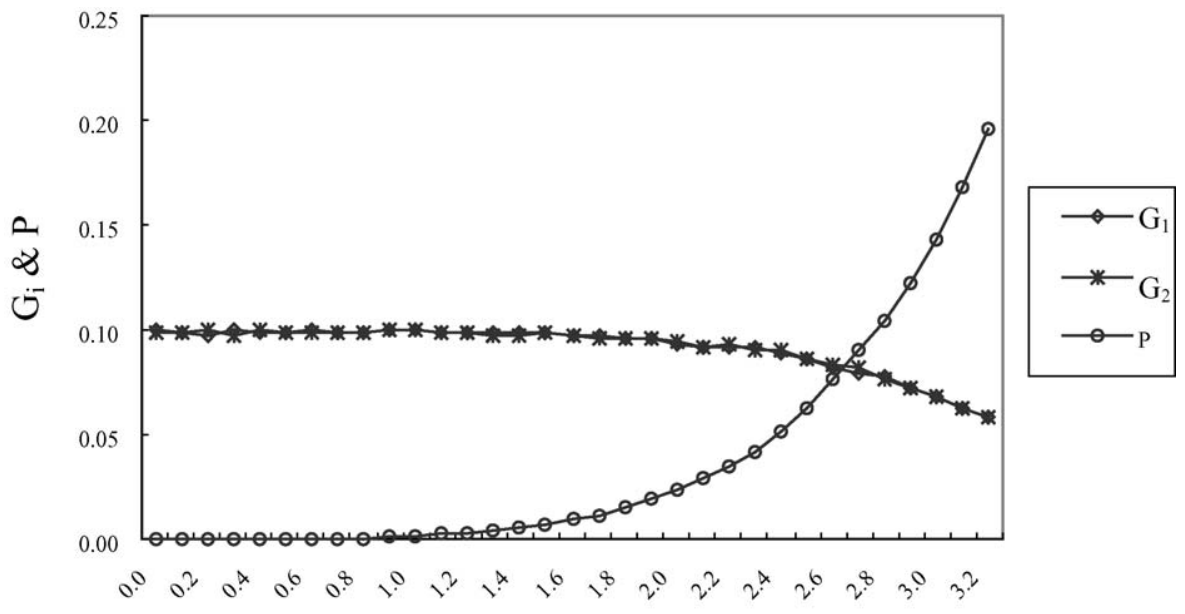

$\mathrm{H}$

Fig. 5. The effects of a change in $H$ on the loan guarantee portfolio value and default probability. $G_{1}$ represents the loan guarantee value (in terms of millions of dollars) for borrowing firm one, $G_{2}$ represents the loan guarantee value (in terms of millions of dollars) for borrowing firm two, and $P$ denotes the default probability of loan guarantee contract, respectively. 


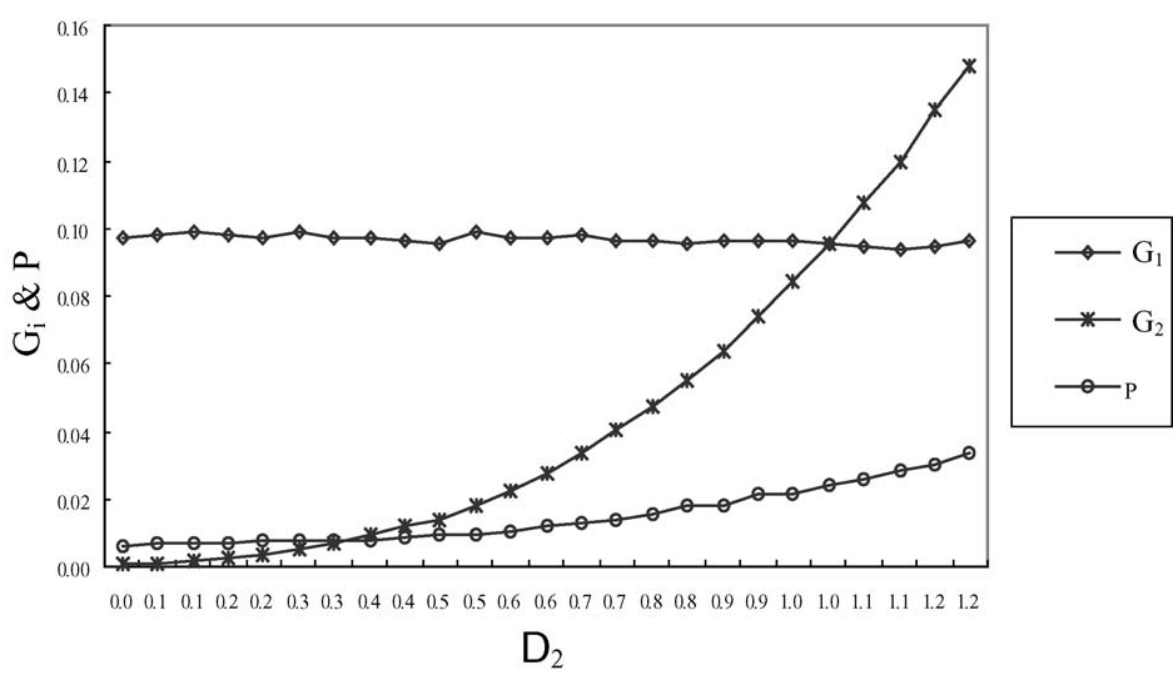

Fig. 6. The effects of a change in $D_{2}$ on the loan guarantee portfolio value and default probability. $G_{1}$ represents the loan guarantee value (in terms of millions of dollars) for borrowing firm one, $G_{2}$ represents the loan guarantee value (in terms of millions of dollars) for borrowing firm two, and $P$ denotes the default probability of loan guarantee contract, respectively.

between the guarantor's firm value and its senior debt values. Hence, other things being equal, the larger the guarantor's senior debts are, the smaller is the compensation for the guarantees and the higher is the default probability. This result is reasonable and intuitive.

Other factors which could affect the value of loan guarantee contracts are the amounts of borrowing firm two's senior debts and its guaranteed debts. Fig. 6 shows that the larger the amount is of borrowing firm two's senior debts, the larger is the value of loan guarantee for borrowing firm two, and the smaller is the value of loan guarantee for borrowing firm one. This result is quite intuitional. When the amount of borrowing firm two's senior debts becomes larger, borrowing firm two is more likely to become bankrupt. Therefore, the loan guarantee contract becomes more valuable for borrowing firm two. In contrast, other things being equal, the value of loan guarantee for borrowing firm one will be smaller. Furthermore, the larger the amount of borrowing firm two's senior debts is, the higher the default probability is. Fig. 7 demonstrates additionally that the larger the amount is of borrowing firm two's guaranteed debts, the larger is the value of loan guarantee for borrowing firm two, the smaller is the value of loan guarantee for borrowing firm one, and the higher is the default probability. The reason for these results is similar to that of Fig. 6 .

\subsection{Results of joint loan guarantees}

As mentioned earlier, it is very common for a large firm with huge amount of loans to seek several banks or insurance companies as its guarantor at the same time. In this subsection, we investigate how important factors affect the value of joint loan guarantees with stochastic interest rates according to the models constructed in Section 3. 


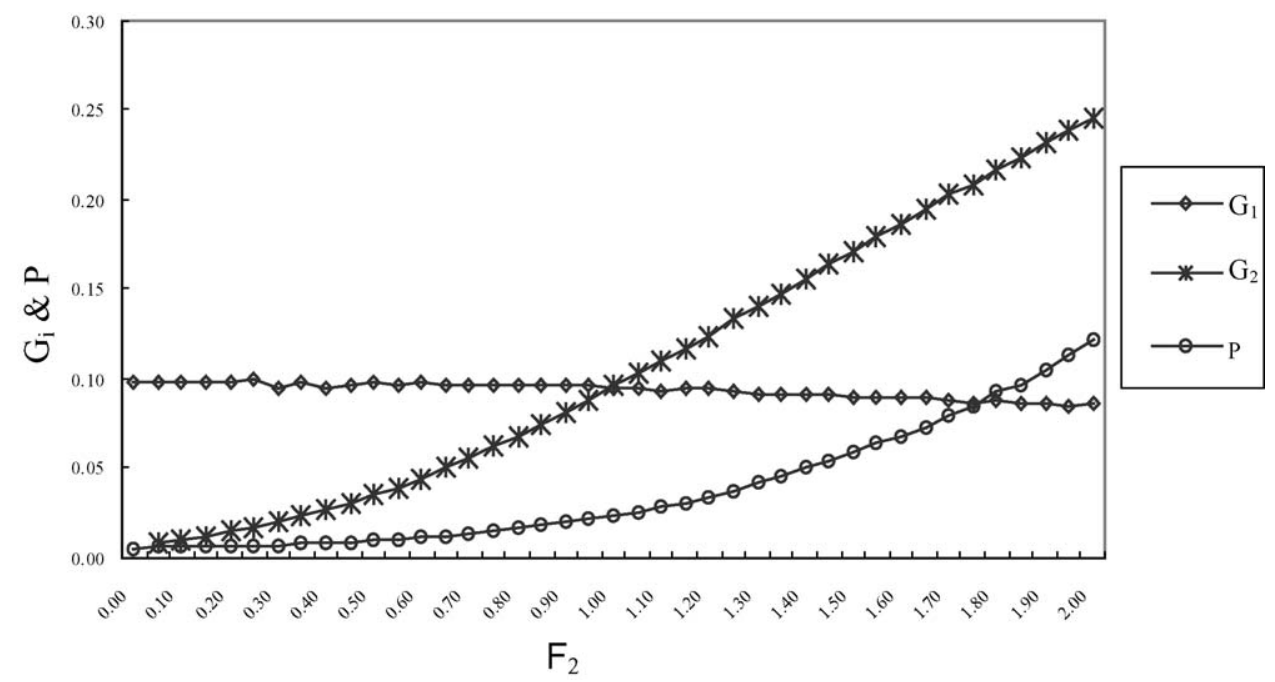

Fig. 7. The effects of a change in $F_{2}$ on the loan guarantee portfolio value and default probability. $G_{1}$ represents the loan guarantee value (in terms of millions of dollars) for borrowing firm one, $G_{2}$ represents the loan guarantee value (in terms of millions of dollars) for borrowing firm two, and $P$ denotes the default probability of loan guarantee contract, respectively.

We first examine the effects of changes in the correlation coefficient between the firm value of guarantor one and that of guarantor two $\left(\rho_{W_{1}, W_{2}}\right)$ on the loan guarantee cost shared by each guarantor (or the corresponding loan guarantee value provided by each guarantor) and the default probability from each guarantor. As reported in Fig. 8, we find that the

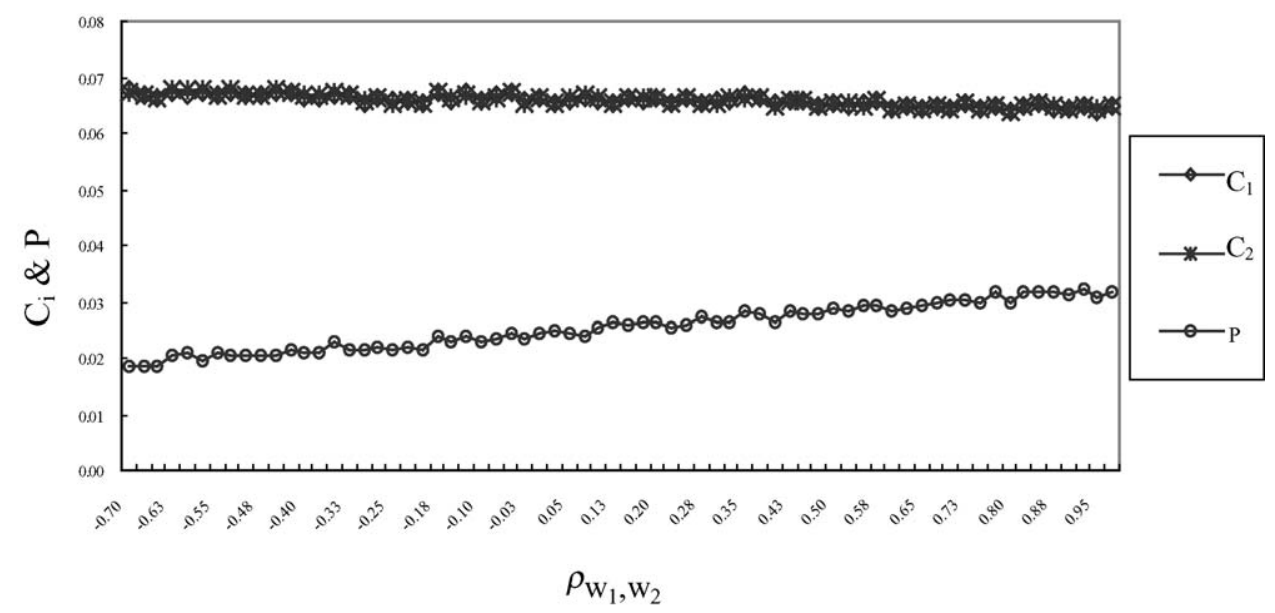

Fig. 8. The effects of a change in $\rho_{W_{1}, W_{2}}$ on the joint loan guarantee value and default probability. $C_{1}$ represents the loan guarantee value (in terms of millions of dollars) provided by guarantor one, $C_{2}$ represents the loan guarantee value provided by guarantor two, and $P$ denotes the default probability of loan guarantee contract, respectively. 


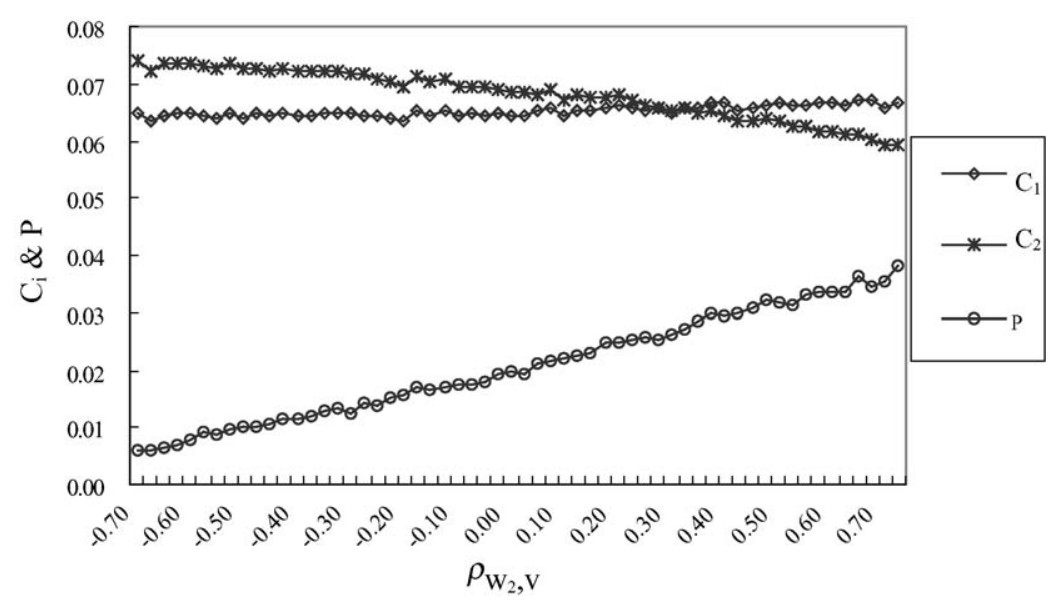

Fig. 9. The effects of a change in $\rho_{W_{2}, V}$ on the joint loan guarantee value and default probability. $C_{1}$ represents the loan guarantee value (in terms of millions of dollars) provided by guarantor one, $C_{2}$ represents the loan guarantee value (in terms of millions of dollars) provided by guarantor two, and $P$ denotes the default probability of loan guarantee contract, respectively.

higher $\rho_{W_{1}, W_{2}}$ is, the smaller is the loan guarantee cost shared by each guarantor and the higher is the default probability. The reason for this result is that the higher $\rho_{W_{1}, W_{2}}$ is, the smaller is the function of risk protection from each guarantor. Hence, the loan guarantee values provided by each guarantor decrease and the default probability increases as the correlation coefficient between the firm value of guarantor one and that of guarantor two increases. Additionally, as shown in Fig. 9, when the correlation coefficient between the firm value of guarantee and the firm value of guarantor two $\left(\rho_{V, W_{2}}\right)$ increase, the loan guarantee value provided by guarantor two decreases, whereas the loan guarantee value provided by guarantor one increase. Furthermore, the default probability also increases when $\rho_{W, V_{2}}$ increases. The reason for these results are similar to those of Fig. 8.

Other potential factors which could significantly affect the loan guarantee values are the correlation coefficient between the firm value of guarantors and the interest rate $\left(\rho_{W_{i}, r}\right)$, and the correlation coefficient between the borrowing firm value and interest rate $\left(\rho_{V, r}\right)$. As reported in Fig. 10, the higher the correlation coefficient is between the firm value of guarantee and the interest rate, the larger is the loan guarantee values, and the higher is the default probability. This result can be explained by Eq. (15). As Eq. (15) shows, the probability of the random term $\sigma_{r} \sqrt{r} \mathrm{~d} Z$ becoming negative will also increase, when the random term $\sigma_{W_{V} \varepsilon_{V}} \sqrt{\mathrm{d} t}$ is negative and causes the guarantee to bankrupt. In this case, the drift term $\sigma_{W_{V} \varepsilon_{V}} \sqrt{\mathrm{d} t}$ will also decrease, and hence the amounts of bankruptcy for the guarantee increase. Therefore, the loan guarantee cost shared by each guarantor will increase. We also find that the higher the correlation coefficient is between guarantor two's value and interest rate, the smaller is the loan guarantee value provided by each guarantor, and the higher is the default probability. The reason for this result is similar to that of Figs. 10 and 11. 


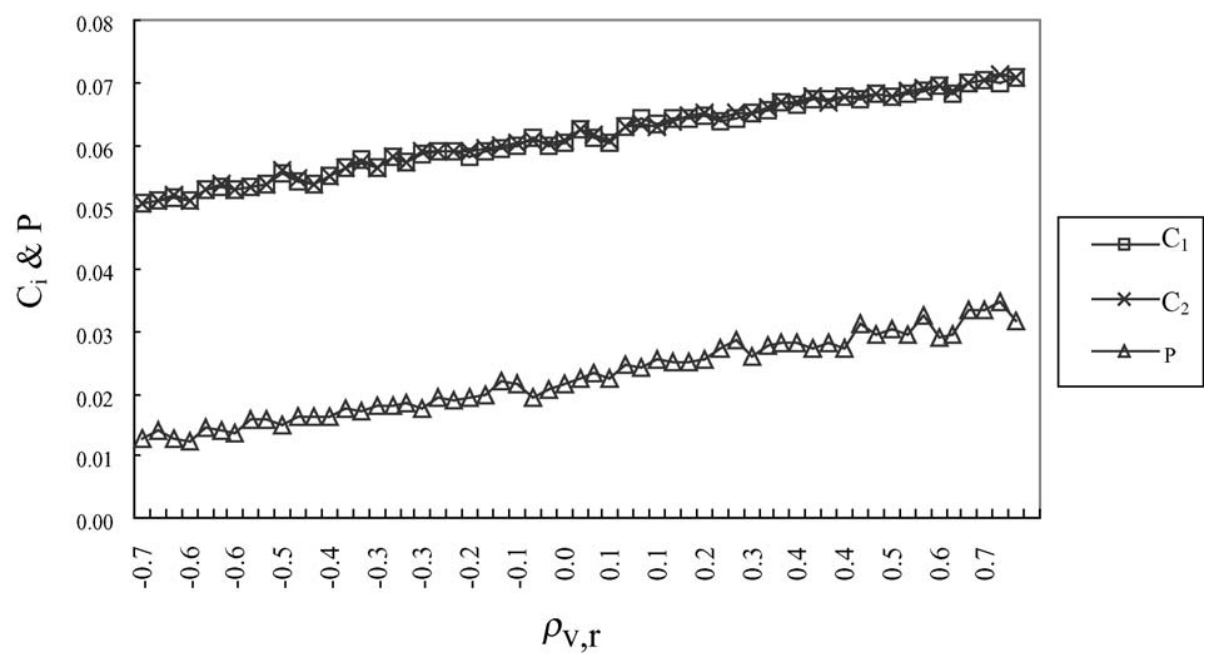

Fig. 10. The effects of a change in $\rho_{V, r}$ on the joint loan guarantee value and default probability. $C_{1}$ represents the loan guarantee value (in terms of millions of dollars) provided by guarantor one, $C_{2}$ represents the loan guarantee value (in terms of millions of dollars) provided by guarantor two, and $P$ denotes the default probability of loan guarantee contract, respectively.

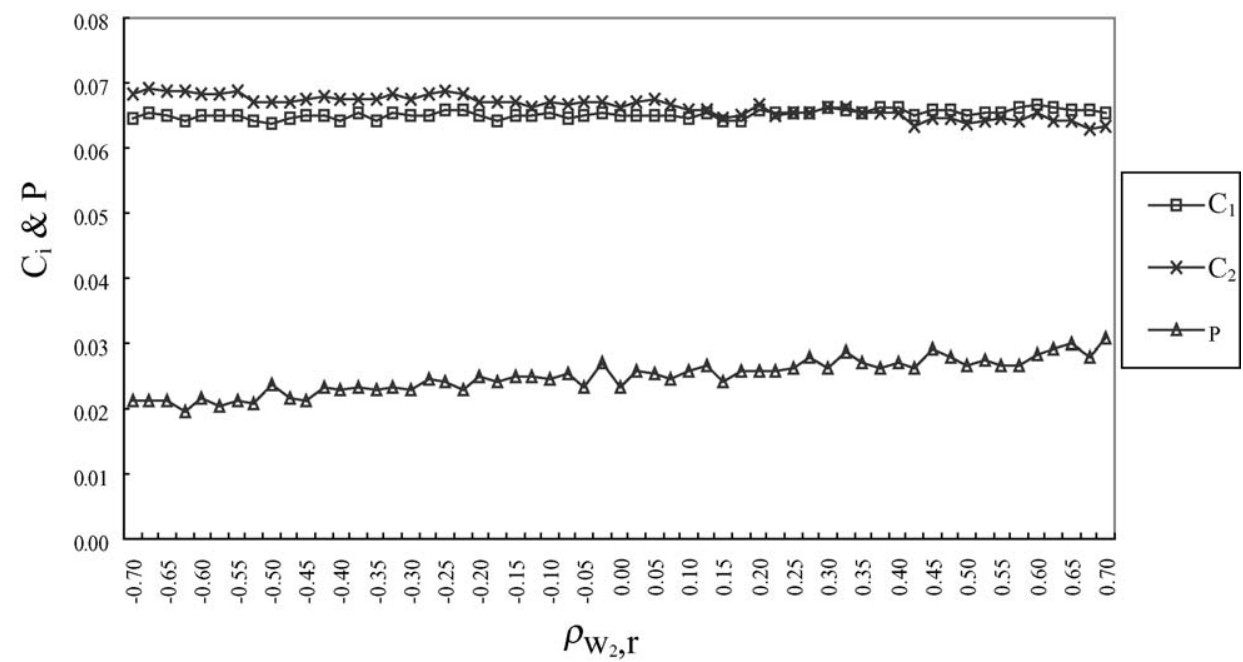

Fig. 11. The effects of a change in $\rho_{W_{2}, r}$ on the joint loan guarantee value and default probability. $C_{1}$ represents the loan guarantee value (in terms of millions of dollars) provided by guarantor one, $C_{2}$ represents the loan guarantee value (in terms of millions of dollars) provided by guarantor two, and $P$ denotes the default probability of loan guarantee contract, respectively. 


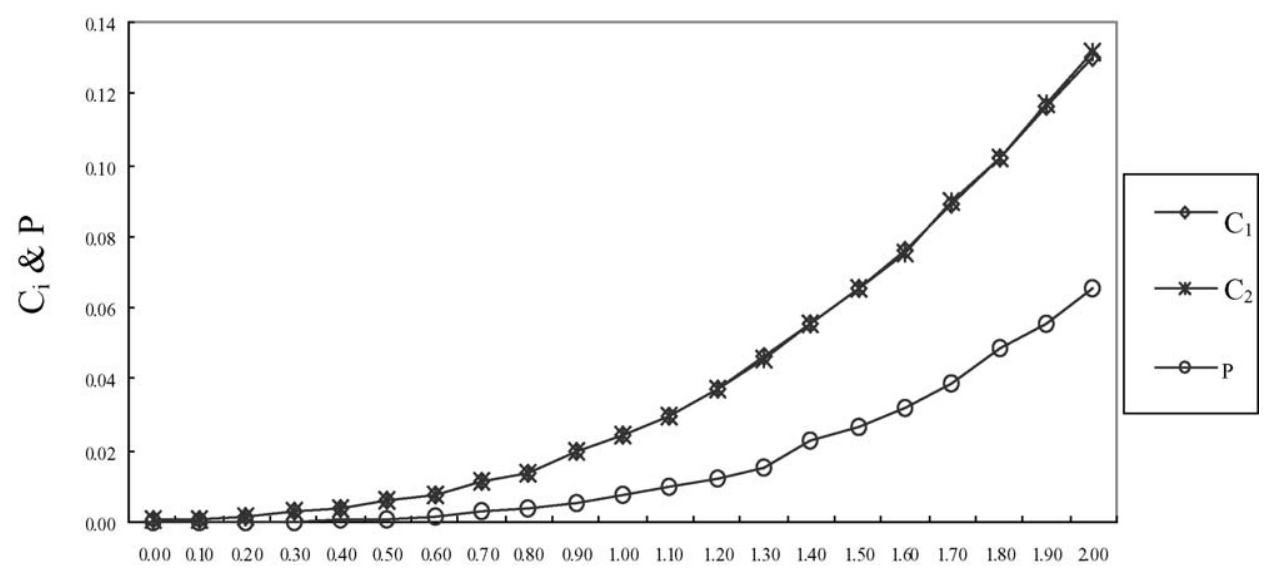

D

Fig. 12. The effects of a change in $D$ on the joint loan guarantee value and default probability. $C_{1}$ represents the loan guarantee value (in terms of millions of dollars) provided by guarantor one, $C_{2}$ represents the loan guarantee value (in terms of millions of dollars) provided by guarantor two, and $P$ denotes the default probability of loan guarantee contract, respectively.

Figs. 12 and 13 demonstrate that as the amounts of guarantee's debt (no matter junior or senior debt) increase, the loan guarantee values provided by each guarantor increase, and the default probability will increase. This result is very intuitive. The risk magnitude of guarantee will increase when the amounts of the guarantee's debt increase. Hence,

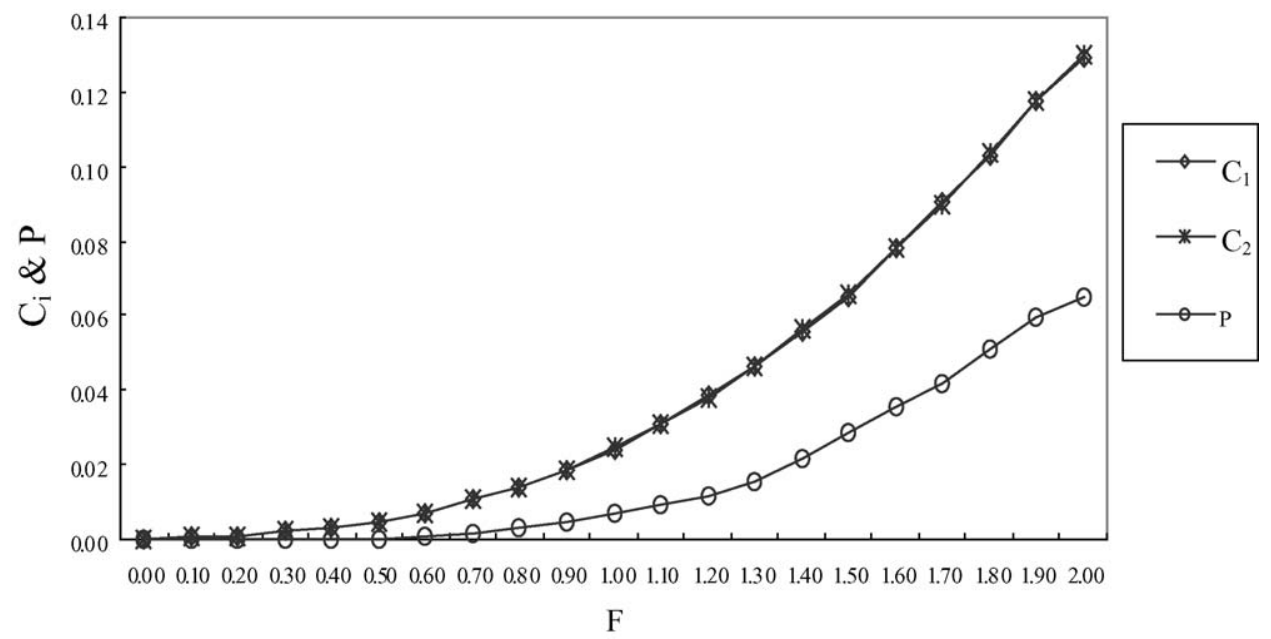

Fig. 13. The effects of a change in $F$ on the joint loan guarantee value and default probability. $C_{1}$ represents the loan guarantee value (in terms of millions of dollars) provided by guarantor one, $C_{2}$ represents the loan guarantee value (in terms of millions of dollars) provided by guarantor two, and $P$ denotes the default probability of loan guarantee contract, respectively. 


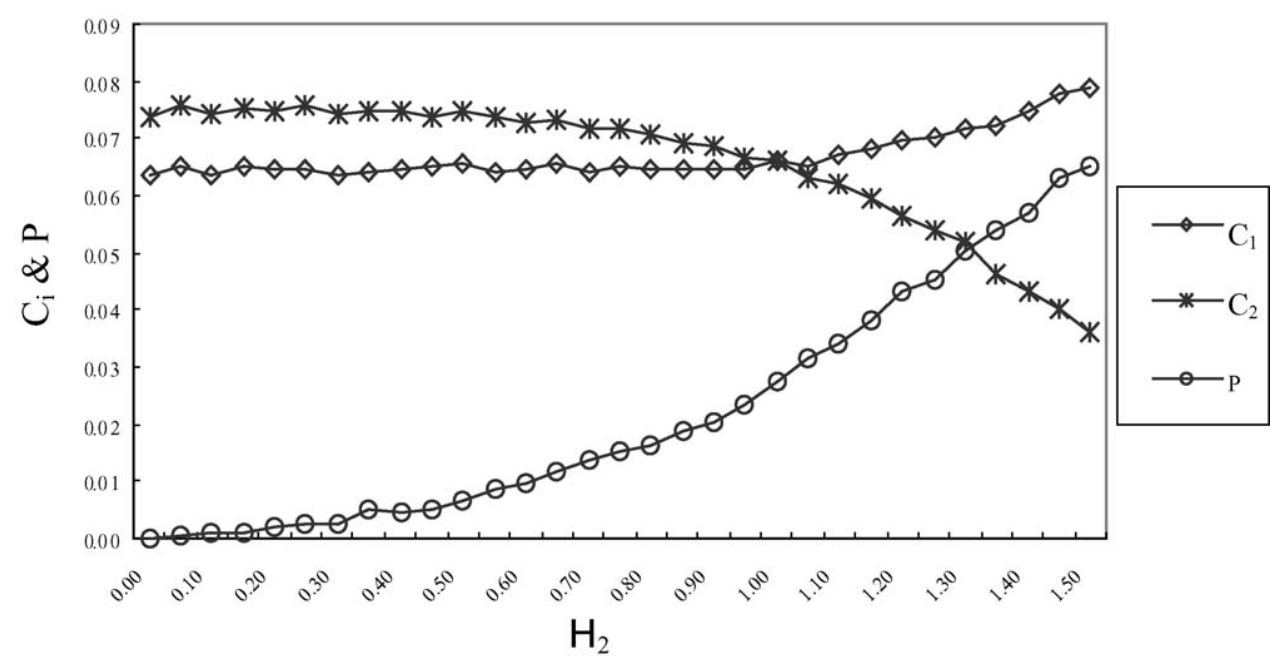

Fig. 14. The effects of a change in $H_{2}$ on the joint loan guarantee value and default probability. $C_{1}$ represents the loan guarantee value (in terms of millions of dollars) provided by guarantor one, $C_{2}$ represents the loan guarantee value (in terms of millions of dollars) provided by guarantor two, and $P$ denotes the default probability of loan guarantee contract, respectively.

the loan guarantee values provided by each guarantor and the default probability will increase.

As reported in Fig. 14, the higher the amount is of guarantor two's senior debt, the smaller is the guarantee value provided by guarantor two, the larger is the guarantee value provided by guarantor one, and the higher is the default probability. The reason can be explained as follows. The compensation amount for the guarantees is equal to the difference between the guarantor's firm value and its senior debt values. Hence, other things being equal, the larger the guarantor's senior debts are, the smaller is the compensation for the guarantees and the higher is the default probability.

\section{Conclusions}

Many real world cases for loan guarantees are one-guarantee and multiple-guarantor, or multiple-guarantee and one-guarantor. For these cases, the models existing in the literature cannot directly be used to estimate the loan guarantee values. In this paper, we construct models which can estimate the loan guarantee values under one-guarantee and multipleguarantors, or multiple-guarantees and one-guarantor with stochastic interest rates. Hence, our paper fills in the existing gap in the literature and provides solutions for valuing the loan guarantee for a general framework.

From the simulation results, we find that the correlation coefficients such as $\rho_{W, V_{2}}$, $\rho_{V_{1}, V_{2}}, \rho_{r, W}, \rho_{r, V_{2}}$, etc. play important roles in the valuation of a loan guarantee con- 
tract. We also find that the amounts of junior debt or senior debt of guarantees or guarantor will significantly affect the value and default probability of loan guarantee contracts.

\section{Acknowledgments}

The earlier version of this paper was presented at the 10th Conference on Theories and Practices of Securities and Financial Markets and the 2002 EFMA annual meeting. We are especially grateful to Bing-Huei Lin and Robin Chow for helpful comments and discussions.

\section{Appendix A}

We describe the process of generating random variables in this appendix. As an illustration, we consider the case of multiple-borrowers and one-guarantor, where the payoff of the loan guarantee depends on $n+2$ variables $\left(W, V_{1}, V_{2}, \ldots, V_{n}, r\right)$. In this case, we need to generate $n+2$ standard normal random variables, $\varepsilon_{i}, i=1,2, \ldots, n$. The correlation coefficient between $\varepsilon_{i}$ and $\varepsilon_{j}$ is $\rho_{i, j}$ for $1 \leq i, j \leq n+2$. One simulation trial involves generating $M$ sample paths of the $\varepsilon_{i}(1 \leq i \leq n+2)$. The required samples of $\varepsilon_{i}$ can be obtained from a multivariate independent standard normal distribution $X$ as follows:

$$
\varepsilon_{i}=\sum_{k=1}^{n+2} \alpha_{i k} X_{k}
$$

For $\varepsilon_{i}$ to have correct variance and the correct correlation with $\varepsilon_{j}$, we must have

$$
\sum_{k=1}^{n+2} \alpha_{i k}^{2}=1
$$

and for all $j<i$,

$$
\sum_{k=1}^{n+2} \alpha_{i k} \alpha_{j k}=\rho_{i, j}
$$

The above linear equations are traditionally solved using the Cholesky decomposition technique. The Cholesky decomposition factorizes a symmetric positive definite matrix. Any symmetric positive definite matrix, $A$, may be written as the product of a lower triangular matrix, $L$, and its transpose, $L^{\mathrm{T}}$, which is an upper triangular matrix. For the case of 
multiple-borrowers and one-guarantor, the correlation matrix is given as Eq. (A.1).

$$
R=\left[\begin{array}{ccccc}
1 & \rho_{W, V_{1}} & \rho_{W, V_{2}} & \cdots & \rho_{W, r} \\
\rho_{V_{1}, W} & 1 & \rho_{V_{1}, V_{2}} & \cdots & \rho_{V_{1}, r} \\
\rho_{V_{2}, W} & \rho_{V_{2}, V_{1}} & 1 & \cdots & \rho_{V_{2}, r} \\
\vdots & \vdots & \vdots & \vdots & \vdots \\
\rho_{r, W} & \rho_{r, V_{1}} & \rho_{r, V_{2}} & \cdots & 1
\end{array}\right] .
$$

To use Cholesky decomposition, we let $R=L L^{\mathrm{T}}$, where

$$
L=\left[\begin{array}{ccccc}
\alpha_{1,1} & 0 & 0 & \ldots & 0 \\
\alpha_{2,1} & \alpha_{2,2} & 0 & \ldots & 0 \\
\vdots & \vdots & \vdots & \vdots & \vdots \\
\alpha_{n+2,1} & \rho_{n+2,2} & \rho_{n+2,3} & \ldots & \rho_{n+2, n+2}
\end{array}\right] .
$$

If $R$ is a positive definite matrix, then $L$ exists. For this case, $n+2$ independent standard normal variables time $L$ can be expressed as the following form:

$$
\varepsilon=\left[\begin{array}{c}
\varepsilon_{1} \\
\varepsilon_{2} \\
\vdots \\
\varepsilon_{n+2}
\end{array}\right]=L X, \quad X=\left[\begin{array}{c}
X_{1} \\
X_{2} \\
\vdots \\
X_{n+2}
\end{array}\right] \stackrel{\text { iid }}{\longrightarrow} N(0, I),
$$

where $I$ is an identical matrix. Using Eq. (A.3), we can easily generate random variables from a multivariate independent standard normal distribution.

\section{References}

Chan, K. C., Karolyi, A. K., Longstaff, F., \& Sanders, A. (1992). An empirical comparison of alternative models of the short-term rates. Journal of Finance, 1209-1227.

Chen, A. H., Chen, K. C., \& Sears, R. S. (1986). The value of loan guarantee: The case of Chrysler Corporation. Research in Finance, 6, 101-117.

Cox, J. C., Ingersoll, J. E., \& Ross, S. A. (1985). Theory of term structure of interest rate. Econometrica, 385-407.

Dermine, J., \& Lajeri, F. (2001). Credit risk and the deposit insurance premium: A note. Journal of Economics and Business, 497-508.

Geske, R. (1979). The valuation of compound options. Journal of Financial Economics, 63-81.

Johnson, H., \& Stulz, R. (1987). The pricing of options with default risk. Journal of Finance, 42, $267-280$.

Jones, E. P., \& Mason, S. P. (1980). The valuation of loan guarantee. Journal of Banking and Finance, 89-107.

Lai, V. S. (1992). An analysis of private loan guarantee. Journal of Financial Services Research, 6, 267-280.

Lai, V. S., \& Gendron, M. (1994). On financial guarantee insurance under stochastic interest rates. The Geneva Papers on Risk and Insurance Theory, 19, 119-137.

Lai, V. S., \& Yu, M. T. (1999). An accurate analysis of vulnerable loan guarantees. Research in Finance, 17, $103-137$. 
Merton, R. C. (1977). An analytic derivation of the cost of deposit insurance and loan guarantees: An application of modern option pricing theory. Journal of Banking and Finance, 1, 3-11.

Merton, R. C., \& Bodie, Z. (1992). On the management of financial guarantees. Financial Management, 21, 87-109.

Selby, M. J. P., Franks, J. R., \& Karki, J. P. (1993). Loan guarantees, wealth transfers and incentives to invest. Journal of Fixed Income, 3, 58-65. 